\title{
Obestatin improves hepatic injury induced by ischemia/reperfusion in rats: Role of nitric oxide
}

\author{
Ola A. El-Gohary \\ Physiology Department, Faculty of Medicine, Benha University, Benha, Qualubia, Egypt
}

\begin{abstract}
Hepatic ischemia/reperfusion (I/R) injury is a common clinical problem. The present study was conducted to evaluate the protective effect of obestatin against I/R-induced liver injury. Rats were divided into three groups $(n=10)$ : control sham-operated group, I/R group and obestatin treatment group. Rats of I/R group and obestatin treatment group underwent partial hepatic ischemia for $60 \mathrm{~min}$ followed by $90 \mathrm{~min}$ reperfusion. At the beginning of the $90-\mathrm{min}$ reperfusion period, rats of obestatin treatment group were injected with obestatin $(100 \mu \mathrm{g} / \mathrm{kg})$ intravenously. At the end of the experiment the animals were sacrificed and blood and liver tissue samples were obtained. Liver function enzymes, alanine aminotransferase (ALT) and aspartate aminotransferase (AST), as well as inflammatory biomarkers, tumor necrosis factor-alpha (TNF- $\alpha$ ) and interleukin-6 (IL-6), were determined in the serum. Also, total oxidative status (TOS), total antioxidant status (TAS) and oxidative stress index (OSI) were measured in hepatic tissue. Liver tissue damage was examined by histopathology. In addition, the expression levels of nitric oxide synthase (NOS) subtypes, endothelial (eNOS) and inducible (iNOS) in liver samples were assessed by Western blotting. Obestatin significantly counteracted I/R-induced liver damage mainly through reducing oxidative stress, inhibiting the release of pro-inflammatory cytokines and modulation of nitric oxide levels.
\end{abstract}

Key words: Obestatin - Ischemia reperfusion - Liver - Nitric oxide - Reactive oxygen species - Inflammatory cytokines

\begin{abstract}
Abbreviations: ALT, alanine aminotransferase; AST, aspartate aminotransferase; eNOS, endothelial synthase; iNOS, inducible synthase; IL, interleukin; I/R, ischemia/reperfusion; NO, nitric oxide; NOS, NO synthase; nNOS, neuronal synthase; OSI, oxidative stress index; ROS, reactive oxygen species; TAS, total antioxidant status; TOS, total oxidant status.
\end{abstract}

\section{Introduction}

Hepatic ischemia/reperfusion (I/R) injury is a major cause of liver dysfunction and is associated with several clinical conditions and interventions including liver transplantation, hepatectomy, and shock. The restoration of the blood supply following a period of ischemia will generally cause I/R injury (Subhas et al. 2010). Liver injury development after the initiation of reperfusion is due to generation of reactive oxygen species (ROS) such as superoxide anion, hydrogen

Correspondence to: Ola A. El-Gohary, Physiology Department, Faculty of Medicine, Benha University, Benha, Qualubia, Egypt E-mail: olaelgohary@yahoo.com peroxide, lipid peroxides, or related species, accumulation of inflammatory cytokines such as tumor necrosis factor alpha (TNF- $\alpha$ ) and interleukins (ILs) and the subsequent biochemical derangements in intracellular homeostasis (MontalvoJave et al. 2008). Nitric oxide (NO) is a key molecule, which is recognized as an important, yet controversial mediator of physiological and pathological processes inherent in I/R injury since it has been shown to have both protective and deleterious effects on cellular functions (Serracino-Inglott et al. 2008). NO is synthesized from L-arginine by three isoforms of the NO synthase (NOS), the endothelial synthase (eNOS), the inducible synthase (iNOS), and the neuronal synthase (nNOS) (Kukreja et al. 2005). eNOS is responsible for the production of basal NO, which maintains normal 
vascular tone. iNOS, contrary to eNOS, is especially induced under oxidative stress conditions, with controversial results regarding its role in ischemia-reperfusion (Kukreja et al. 2005; Abu-Amara et al. 2015). Neuronal (nNOS) is involved in neural signaling with no participation in the I/R events (Zhou and Zhu 2009).

Obestatin is a circulating 23-amino-acid peptide hormone, encoded by the same gene as ghrelin (Li et al. 2011). It is predominantly produced in the stomach, and exhibits a wide range of peripheral effects including inhibition of food intake, body weight gain, gastric emptying and regulation of jejunal motility ( $\mathrm{Li}$ et al. 2011; Trovato et al. 2014). In specific, we tested the hypothesis that obestatin exerts a protective effect on the liver, as this has been evidenced for other tissues subjected to I/R insults, with a trial to clarify some of the possible involved mechanisms. In an attempt to elaborate the mechanism of the potential hepatoprotective effects of obestatin, we investigated its effect on the redox status of the liver by assessing the levels of lipid peroxides. We also assessed its anti-inflammatory effect through estimation of inflammatory biomarkers. In addition, the expression levels of nitric oxide synthetase subtypes (eNOS and iNOS) in liver samples were assessed by Western blotting.

\section{Material and Methods}

\section{Animals}

This study was conducted on 30 adult Wistar albino male rats, 6-8 weeks old, weighing between 200 and 250 g. Animals were housed in the animal laboratory at the medical research center of Benha faculty of medicine. They were housed at room temperature $\left(25^{\circ} \mathrm{C}\right)$ and $12 \mathrm{~h} / 12 \mathrm{~h}$ light/ dark cycle. All rats were fed a standard diet and water. The study was carried out according to the guidelines of the Ethics Committee, Faculty of Medicine, Benha University.

\section{Experimental design}

Rats were randomly divided into three groups $(n=10)$ : Group I: Control sham group $(n=10)$. Portal structures of the left and middle liver lobe were isolated, but did not clamp, and the abdomen was subsequently closed without treatment and medication.

Group II: Hepatic I/R group $(n=10)$. Animals underwent partial hepatic ischemia for $60 \mathrm{~min}$ followed by $90 \mathrm{~min}$ of reperfusion.

Group III: Obestatin group $(n=10)$. Animals underwent partial hepatic ischemia for $60 \mathrm{~min}$ and at the beginning of the 90 -min reperfusion period; the rats were injected with obestatin $(100 \mu \mathrm{g} / \mathrm{kg}$ ) intravenously (iv) (Şen et al. 2015).

\section{Hepatic I/R injury}

The overnight fasting animals were anesthetized with intraperitoneal administration of ketamine $50 \mathrm{mg} / \mathrm{kg}$ and xylazine $5 \mathrm{mg} / \mathrm{kg}$. The abdomen was shaved and disinfected with $75 \%$ ethanol. A midline incision was performed and the hilum of the liver was exposed. All structures in the portal triad (hepatic artery, portal vein and bile duct) to the left and median liver lobes were occluded by a clamp in order to produce $70 \%$ hepatic ischemia. Sixty minutes later, the ischemic liver was reperfused by opening the clamp and reperfusion was achieved for $90 \mathrm{~min}$ (Zhai et al. 2004). At the end of the experimental procedure the animals were sacrificed and blood and liver tissue samples were obtained for further biochemical and histopathological investigations.

\section{Biochemical analysis}

The serum was separated by centrifugation (5000 rpm for $5 \mathrm{~min}$ ) and used for biochemical analysis. The activities of liver enzymes such as alanine aminotransferase (ALT, a specific marker for hepatic parenchymal injury), and aspartate aminotransferase (AST, a nonspecific marker for hepatic injury) were determined by a standard automated technique using Hitachi Analyzer Model 911 and adequate kits from Roche Company (Switzerland). In addition inflammatory markers such as TNF- $\alpha$ and IL- 6 were determined by ELISA technique using standard kits (Ray Biotech, Inc., USA).

\section{Determination of oxidative stress biomarkers}

The liver was dissected out and a part from its left lobe was washed with saline, dried and homogenized in $50 \mathrm{mmol} / \mathrm{l}$ phosphate buffer (ice cold) solution ( $\mathrm{pH} 7.4$ ) to give $20 \%$ homogenate (w/v) (Lin et al. 1998). The homogenate was centrifuged at $3000 \times g$ for $20 \mathrm{~min}$. The supernatant was separated and stored at $-80^{\circ} \mathrm{C}$ till the colormetric determination of total oxidant status (TOS) and total antioxidant status (TAS) using UV-160 1PC UV-visible spectrophotometer. For reading the absorbance was used Kits produced by Biodiagnostic Co., Egypt. The percent ratio TOS/TAC gave the oxidative stress index (OSI), an indicator of the degree of oxidative stress (Harma et al. 2003).

\section{Western blotting}

Proteins were extracted from liver tissues, which were subjected to ischemia and their concentrations were determined by the Bradford assay (Bio-Rad, CA, USA). Equivalent amounts of proteins were subjected to 10\% SDS polyacrylamide gel electrophoresis. Blots were transferred onto a nitrocellulose membrane using a semidry transfer 
cell. After blocking, the membranes were then incubated with the appropriate primary and then secondary antibodies. The immunoblots were detected using enhanced chemiluminescence (Omar et al. 2011).

\section{Histopathological examination}

Liver specimens of the left lobe were sectioned, fixed in $10 \%$ formalin buffer and embedded in paraffin. The sections were cut into $5-\mu \mathrm{m}$ sections and stained with hematoxylin/eosin (H\&E) for histological examination with a light microscope.

\section{Chemicals}

Obestatin was purchased from Sigma Aldrich Company (USA). It was supplied as white powder and dissolved in deionized water.

\section{Statistical analysis}

All analyses were performed using the program "Statistical Package for Social Sciences (SPSS) version 16" (SPSS Inc, Chicago, IL, USA). The data are presented as the mean \pm standard deviation (SD). Comparisons among groups, in all studied parameters, were analyzed by using One-way analysis of variance (ANOVA) test and Post Hoc multiple comparisons (LSD test). Probability $p<0.05$ was considered statistically significant.

\section{Results}

Effects of obestatin on liver enzymes and inflammatory markers

Hepatic I/R significantly increased serum ALT and AST $(p<0.05)$ in I/R group compared to control group. The rise of these enzymes showed significant reduction $(p<0.05)$ by prior administration of obestatin (Table 1).

As regard pro-inflammatory cytokines, TNF- $\alpha$ and IL-6 increased significantly $(p<0.05)$ in $\mathrm{I} / \mathrm{R}$ rats compared to normal rats. However, these cytokines were decreased significantly $(p<0.05)$ in obestatin group compared to I/R group (Table 1).

\section{Effects of obestatin on oxidative stress biomarkers}

I/R increased TOS and OSI in hepatic tissue significantly $(p<0.05)$ with a parallel significant decrease in TAS $(p<0.05)$ as compared to control group. However, obestatin treatment resulted in a significant decrease in TOS and OSI levels $(p<0.05)$ and a significant increase in TAS level $(p<0.05)$ as compared to the I/R group (Table 2 ).

\section{Western blotting of iNOS and eNOS}

I/R significantly decreased the expression of eNOS $(p<0.05)$ as compared to control group. Pretreatment with obestatin antagonized I/R-induced expression of eNOS as compared to ischemic group. With regard to iNOS, I/R group showed a significant increase $(p<0.05)$ in the expression of iNOS as compared to control rats. Obestatin treatment significantly decreased the expression of iNOS as compared to ischemic group (Table 3 ).

Table 1. Effects of obestatin on serum liver enzymes and inflammatory markers in rats subjected to $\mathrm{I} / \mathrm{R}$

\begin{tabular}{lrcr}
\hline & $\begin{array}{c}\text { Control } \\
\text { group }\end{array}$ & $\begin{array}{c}\text { I/R } \\
\text { group }\end{array}$ & $\begin{array}{c}\text { Obestatin } \\
\text { group }\end{array}$ \\
\hline ALT $(\mathrm{U} / \mathrm{l})$ & $25.2 \pm 6.7$ & $112.6 \pm 1.9^{\star}$ & $78.3 \pm 3.5^{\star *}$ \\
AST $(\mathrm{U} / \mathrm{l})$ & $112.6 \pm 8.2$ & $224.1 \pm 11.3^{\star}$ & $136.3 \pm 4.8^{\star *}$ \\
TNF- $\alpha(\mathrm{pgm} / \mathrm{ml})$ & $31.4 \pm 4.2$ & $129.3 \pm 3.4^{\star}$ & $62.6 \pm 8.3^{\star *}$ \\
$\mathrm{IL}-6(\mathrm{pgm} / \mathrm{ml})$ & $51.6 \pm 6.5$ & $243.1 \pm 4.7^{\star}$ & $92.4 \pm 6.6^{\star *}$ \\
\hline
\end{tabular}

Data are mean $\pm \mathrm{SD}, n=10 .{ }^{\star} p<0.05$ significant difference compared with control group; ${ }^{* *} p<0.05$ significant difference compared with I/R group. ALT, alanine aminotransferase; AST, aspartate aminotransferase; TNF- $\alpha$, tumor necrosis factor $\alpha$; IL-6, interleukin-6.

Table 2. Effects of obestatin on liver oxidative stress markers in rats subjected to $\mathrm{I} / \mathrm{R}$

\begin{tabular}{lccr}
\hline & $\begin{array}{c}\text { Control } \\
\text { group }\end{array}$ & $\begin{array}{c}\text { I/R } \\
\text { group }\end{array}$ & $\begin{array}{c}\text { Obestatin } \\
\text { group }\end{array}$ \\
\hline TOS (nmol/mg protein) & $9.8 \pm 1.2$ & $16.4 \pm \mathbf{1 . 5}^{\star}$ & $12.6 \pm 2.2^{\star *}$ \\
TAS (nmol/mg protein) & $2.5 \pm 4.7$ & $1.2 \pm 2.8^{\star}$ & $2.7 \pm 3.1^{\star *}$ \\
OSI (\%) & $3.2 \pm 0.7$ & $7.6 \pm 0.9^{\star}$ & $3.9 \pm 0.9^{\star *}$ \\
\hline
\end{tabular}

Data are mean $\pm \mathrm{SD}, n=10 .{ }^{\star} p<0.05$ significant difference compared with control group; ${ }^{*} p<0.05$ significant difference compared with I/R group. TOS, total oxidant status; TAS, total antioxidant status; OSI, oxidative stress index.

Table 3. Effects of obestatin on I/R-induced iNOS and eNOS expression in rat hepatic tissues measured by Western blotting

\begin{tabular}{lccc}
\hline & $\begin{array}{c}\text { Control } \\
\text { group }\end{array}$ & $\begin{array}{c}\text { I/R } \\
\text { group }\end{array}$ & $\begin{array}{c}\text { Obestatin } \\
\text { group }\end{array}$ \\
\hline eNOS ( $\mu \mathrm{g} /$ gm wet tissue) & $1.5 \pm 0.02$ & $0.4 \pm 0.07^{\star}$ & $0.9 \pm 0.06^{\star *}$ \\
iNOS( $\mu \mathrm{g} /$ gm wet tissue) & $0.1 \pm 0.05$ & $0.7 \pm 0.08^{\star}$ & $0.3 \pm 0.04^{\star *}$ \\
\hline
\end{tabular}

Data are mean $\pm \mathrm{SD}, n=10 .{ }^{\star} p<0.05$ significant difference compared with control group; ${ }^{*} p<0.05$ significant difference compared with I/R group. eNOS, endothelial nitric oxide synthase; iNOS, inducible nitric oxide synthase. 
A

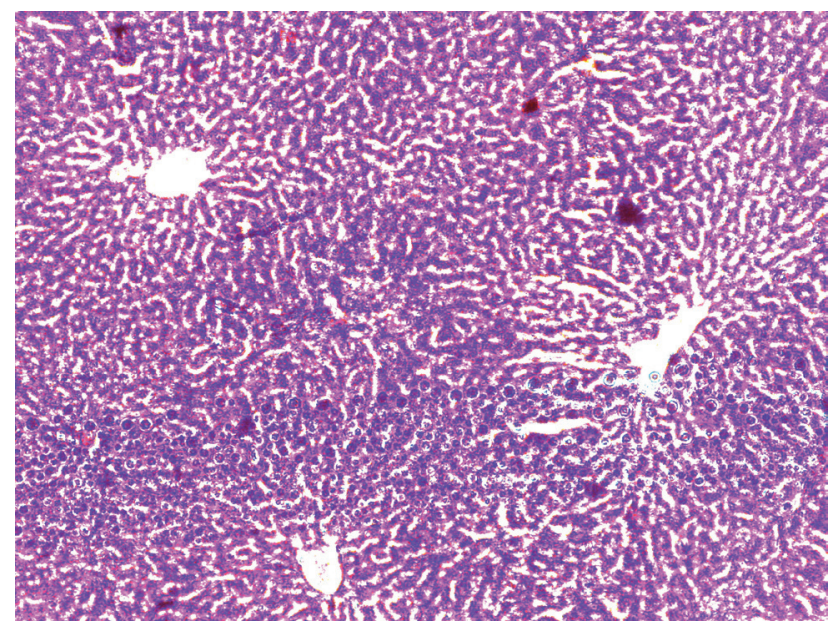

B

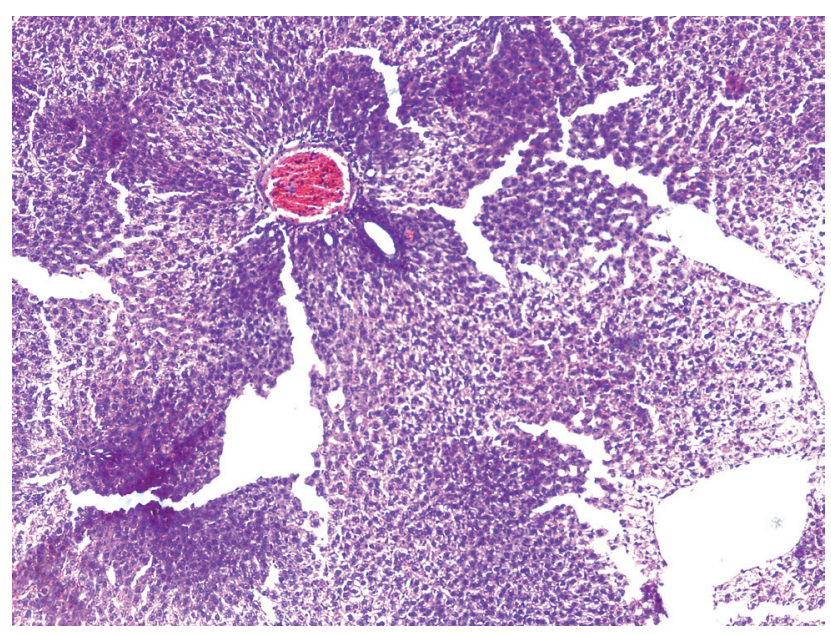

C

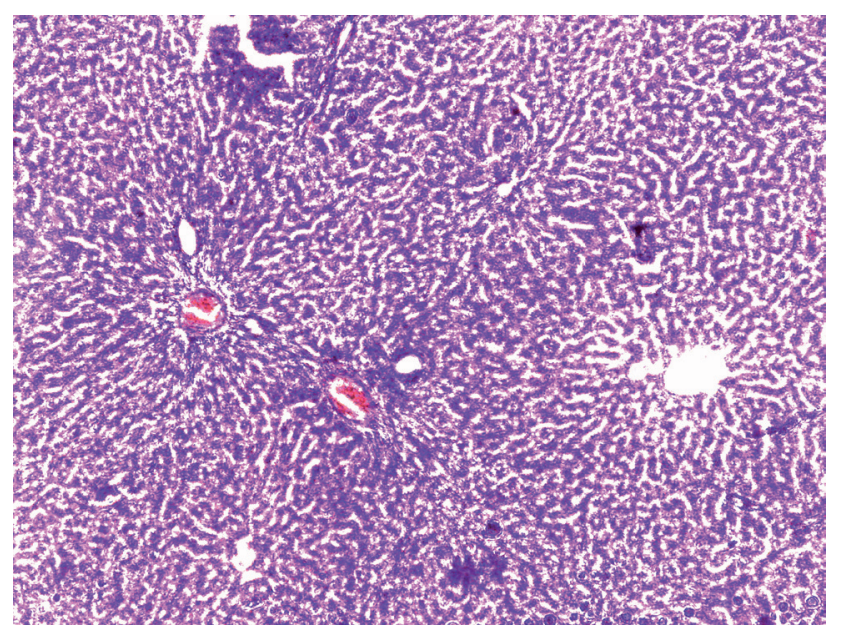

Figure 1. Histopathological examination of rat hepatic tissue of Control group (A), I/R group (B) and Obestatin group (C). H\&E stain, original magnification $\times 200$. For more details see Material and Methods.
Histopathological examination

Histopathological findings in the control group showed normal hepatic architecture with central vein and radiating hepatic cords. In I/R group, dilated and congested portal venule with perivenular necrosis and inflammatory cells infiltration were observed. In contrast, obestatin group showed restoration of hepatocytes and less inflammatory cells infiltration (Figure 1).

\section{Discussion}

Hepatic I/R injury is observed following major liver surgery, transplantation, trauma and sepsis and may cause metabolic and structural hepatic damage (Van Gulik et al. 2007; Shin et al. 2008). This remains a significant problem in surgical procedures, and is a limiting factor in liver transplantation (He et al. 2005). Because of the complicated pathophysiology of I/R-induced liver injury, many researches have been done to find the optimal measures and treatments to protect against the post ischemic hepatocyte damage.

Obestatin is a newly discovered peptide, which derives from the ghrelin peptide precursor pre-pro-ghrelin (Zhang et al. 2005; Pemberton and Richards 2008; Ren et al. 2009). Although it has been suggested that obestatin participate in a complex regulatory system (Soares et al. 2008), the role of obestatin in pathophysiological conditions are largely unknown. Recent studies have shown that obestatin exhibits protective and regenerative effects in some organs including the stomach, kidney, brain and the pancreas. However, no studies investigated the effect of obestatin administration on the liver. To elucidate the potential hepatoprotective effects of obestatin, hepatic I/R injury was induced in male rats. Previous studies have shown that inflammation, apoptosis, and altered microcirculation are evidently found even in the early stage of hepatic I/R injury.

In the present study, ALT and AST levels significantly elevated after I/R most likely due to cell membrane damage. These findings are in agreement with those of Sepodes et al. (2006). ALT and AST levels are generally measured as indirect biochemical indices of liver injury (Niemelä and Alatalo 2010). Obestatin treatment markedly attenuated ALT, AST levels, suggesting a possible protective effect of obestatin treatment in the hepatic I/R condition.

In the current study, it was preferred to measure oxidants and antioxidant capacity simultaneously to assess oxidative stress more exactly. TOS was evaluated to reflect the oxidative status, while TAS was evaluated to reflect the antioxidative status. Also OSI was taken as an indicator of the degree of oxidative stress. The data of the present study confirm that liver $\mathrm{I} / \mathrm{R}$ increases oxidative stress, an effect that not only produces direct tissue damage, but also modulates produc- 
tion of inflammatory cytokines (TNF- $\alpha$ and IL-6). These findings are in line with a recent study of Sözen et al. (2011). During I/R, the antioxidant enzyme levels rapidly decrease and ROS is produced and begins to damage various cellular molecules, contributing to further pathological complications (Czubkowski et al. 2010; Klune and Tsung 2010). Lee and Lee (2006) and Gedik et al. (2008) suggested that oxidant stress is the major cause of hepatic I/R injury and that excessive ROS cause tissue damage and cell death by binding and altering cellular macromolecules, including DNA, proteins and lipids, and affect their function. Hepatic I/R results in an enhanced spontaneous release of inflammatory cytokines such as TNF- $\alpha$ and interleukins by Kupffer cells early after reperfusion (Wanner et al. 1996; Mehany et al. 2013). These mediators activate the chemotaxis of neutrophils, which in-turn produce more ROS and increase the production of TNF- $\alpha$ from Kuppfer cells and consequently cause more hepatocyte damage (Mehany et al. 2013; Perry et al. 2013). Obestatin treatment significantly ameliorated the I/R injury of the liver, as shown by decreased oxidative parameters (TOS and OSI), increased antioxidative parameter (TAS) and markedly reduced pro-inflammatory cytokines (TNF- $\alpha$ and IL-6). This conforms to the recent data published by Koç and colleagues (2014) regarding the anti-oxidative and anti-inflammatory effect of obestatin.

Furthermore, I/R group in the present model showed a significant increase in iNOS expression and a significant decrease in eNOS expression. These results match those reported by Mizar et al. (2015). Emerging evidence suggests that NO has an important role in ischemia injury; however there are conflicting reports regarding the action of $\mathrm{NO}$ in reperfusion damage. Several reports suggested that moderate levels of NO, generated by eNOS, may be beneficial for its vasodilator action, whereas high levels of NO, produced by iNOS, interacting with superoxide anion to produce peroxynitrite, a potent oxidant associated to pathological liver conditions (Beckman et al. 1990; Koken and Inal 1999). Moreover, NO generated by iNOS, may induce inflammatory cell infiltration and parenchyma cell dysfunction (Lanteri et al. 2003). It is considered that endogenous (basal) NO, produced by eNOS, protects both hepatocytes and endothelial cells against reperfusion injury in the liver (Cottart et al. 1999). NO counteracts the vasoconstriction caused by endothelin-1, which is involved in microvascular dysfunction, particularly during the early stages of liver I/R (Datta et al. 2013). Therefore, eNOS expression seems to have a cytoprotective effect through maintaining basal levels of NO production and acts protectively against the early phase of I/R injury by preservation of the sinusoidal structure and maintenance of blood flow through the hepatic microcirculation, thus limiting the extent of I/R injury (Serracino-Inglott et al. 2003; Kukreja et al. 2005). eNOS expression is downregulated during liver reperfu- sion as a result of inhibition of eNOS activity by oxidative stress and absence of flow within the sinusoids during ischemia (Serracino-Inglott et al. 2003). The decreased production of NO from eNOS increases the vascular resistance of the intrahepatic circulation and contributes to the microcirculatory failure following reperfusion (Vollmar et al. 1994; Menger et al. 1999). On the other hand, the induction of iNOS, stimulated by oxidative stress during reperfusion seems to increase reperfusion-mediated liver injury (Kukreja et al. 2005; Abu-Amara et al. 2012). Once iNOS is induced, excessive amounts of NO are produced. In the presence of superoxide, $\mathrm{NO}$ can form peroxynitrite, a potent oxidant and protein nitrating agent and a substance extremely toxic to cells (Beckman et al. 1990). Treatment with obestatin resulted in amelioration of NO expression changes reported in I/R group, an effect that is in accordance with the work of Koç et al. (2014). Obestatin has been shown to upregulate eNOS expression, thus directly enhancing NO bioavailability. Obestatin ameliorates renal I/R injury through modulation of NO metabolism. Vascular relaxation caused by obestatin appears to be mediated by endothelium-dependent NO release via a signaling cascade involving an adenylate cyclase-linked GPCR, PI3K/PKB and $\mathrm{Ca}^{2+}$-dependent eNOS activation. Obestatin binds to an adenylate cyclase (AC)-linked GPCR, thereby promoting PI3K/PKB-, $\mathrm{Ca}^{2+}$-dependent eNOS activation (Agnew et al. 2012).

\section{Conclusion}

Obestatin, a newly discovered peptide provides a hepatoprotective effect against I/R-induced liver damage via reducing oxidative stress and inflammatory process and improving antioxidant activity thus restoring normal live architecture. The significant protective role provided by obestatin against I/R injury appears to be closely related to NO production.

Declaration of interest statement. The author declares that there is no conflict of interest.

\section{References}

Abu-Amara M., Yang S. Y., Seifalian A., Davidson B., Fuller B. (2012): The nitric oxide pathway_evidence and mechanisms for protection against liver ischaemia reperfusion injury. Liver International. 32, 531-543 https:/doi.org/10.1111/j.1478-3231.2012.02755.x

Agnew A. J., Robinson E., McVicar C. M., Harvey A. P., Ali I. H., Lindsay J. E., McDonald D. M., Green B. D., Grieve D. J. (2012): The gastrointestinal peptide obestatin induces vascular relaxation via specific activation of endothelium-dependent NO signaling. Br. J. Pharmacol. 166, 327-338 
https:/doi.org/10.1111/j.1476-5381.2011.01761.x

Beckman J. S., Beckman T. W., Chen J., Marshall P. A., Freeman B. A. (1990): Apparent hydroxyl radical production by peroxynitrite: implications for endothelial injury from nitric oxide and superoxide. Proc. Natl. Acad. Sci. USA 87, 1620-1624 https:/doi.org/10.1073/pnas.87.4.1620

Cottart C., Do L., Blanc M., Vaulbourdolle M., Descamps G., Durand D., Galen F. X., Clot J. P. (1999): Hepatoprotective effect of endogenous nitric oxide during ischemia- reperfusion in the rat. Hepatology 29, 809-813 https:/doi.org/10.1002/hep.510290317

Czubkowski P., Socha P., Pawlowska J. (2010): Current status of oxidative stress in pediatric liver transplantation. Pediatr. Transplant. 14, 169-177 https:/doi.org/10.1111/j.1399-3046.2009.01256.x

Datta G., Fuller B. J., Davidson B. R. (2013): Molecular mechanisms of liver ischemia reperfusion injury: insights from transgenic knockout models. World J. Gastroenterol. 19, 1683-1698 https:/doi.org/10.3748/wjg.v19.i11.1683

Gedik E., Girgin S., Ozturk H., Obay B. D., Ozturk H., Buyukbayram H. (2008): Resveratrol attenuates oxidative stress and histological alterations induced by liver ischemia/reperfusion in rats. World J. Gastroenterol. 14, 7101-7106 https:/doi.org/10.3748/wjg.14.7101

Harma M., Harma M., Erel O. (2003): Increased oxidative stress in patients with hydatidiform mole. Swiss Med. Wkly. 133, 563-566

He X. S., Ma Y., Wu L. W., Wu J. L., Hu R. D., Chen G. H. (2005): Dynamical changing patterns of glycogen and enzyme histochemical activities in rat liver graft undergoing warm ischemia injury. World J. Gastroenterol. 11, 2662-2665

https:/doi.org/10.3748/wjg.v11.i17.2662

Klune J. R., Tsung A. (2010): Molecular biology of liver ischemia/ repefusion injury: established mechanisms and recent advancements. Surg. Clin. North Am. 90, 665-677 https:/doi.org/10.1016/j.suc.2010.04.003

Koç M., Kumralb Z. N. O, Özkanc N., Memid G., Kaçare O., Bilsele S., Çetinelc S., Yeğenb, B. C. (2014): Obestatin improves ischemia/reperfusion-induced renal injury in rats via its antioxidant and anti-apoptotic effects: Role of the nitric oxide. Peptides 60, 23-31 https:/doi.org/10.1016/j.peptides.2014.07.019

Koken T., Inal M. (1999): The effect of nitric oxide on ischemiareperfusion injury in rat liver. Clin. Chim. Acta 288, 55-62 https:/doi.org/10.1016/S0009-8981(99)00138-2

Kukreja R. C., Salloum F., Das A., Ockaili R., Yin C., Bremer Y. A., Fisher P. W., Wittkamp M., Hawkins J., Chou E. et al. (2005): Pharmacological preconditioning with sildenafil: basic mechanisms and clinical implications. Vascul. Pharmacol. 42, 219-232 https:/doi.org/10.1016/j.vph.2005.02.010

Lanteri R., Greco R., Licitra E., Di Benedetto F., Li Destri G., Di Cata- ldo A. (2003): Ischemia and hepatic reperfusion: Is it possible to reduce he- patic alterations? Microsurgery 23, 458-460 https:/doi.org/10.1002/micr.10170

Lee W. Y., Lee S. M. (2006): Synergistic protective effect of ischemic preconditioning and allopurinol on ischemia/ reperfusion injury in rat liver. Biochem. Biophys. Res. Commun. 349, 1087-1093 https:/doi.org/10.1016/j.bbrc.2006.08.140

Li J. B., Asakawa A., Cheng K., Li Y., Chaolu H., Tsai M., Inui A. (2011): Biological effects of obestatin. Endocrine 39, 205-211 https:/doi.org/10.1007/s12020-011-9453-6

Lin C. C., Hsu Y. F., Lin T. C., Hsu F. L., Hsu H. Y. (1998): Antioxidant and hepatoproductive activity of punicalagin and punicalin on carbon tetrachloride induced liver damage in rats. J. Pharmacol. 5, 789-794 https:/doi.org/10.1111/j.2042-7158.1998.tb07141.x

Mehany H. A., Abo-youssef A. M., Ahmed L. A., Arafa S. A., Abd El-Latif H. A. (2013): Protective effect of vitamin E and atorvastatin against potassium dichromate-induced nephrotoxicity in rats J. Basic Appl. Sci. 2, 96-102 https:/doi.org/10.1016/j.bjbas.2013.02.002

Menger M. D., Richter S., Yamauchi J., Vollmar B. (1999): Role of microcirculation in hepatic ischemia/reperfusion injury. Hepatogastroenterology 46, 1452-1457

Mizar S. M., Omar H. A., El Sherbiny G. A., El-moselhy M. A. (2015): Nebivolol and chrysin protect the liver against ischemia/ reperfusion-induced injury in rats. 4, 86-92 https:/doi.org/10.1016/j.bjbas.2015.02.012

Montalvo-Jave E. E., Escalante-Tattersfield T., Ortega-Salgado J. A., Pina E., Geller D. A. (2008): Factors in the pathophysiology of the liver ischemia-reperfusion injury. J. Surg. Res. 147, 153-159 https:/doi.org/10.1016/j.jss.2007.06.015

Niemelä O., Alatalo P. (2010): Biomarkers of alcohol consumption and related liver disease. Scand. J. Clin. Lab. Invest. 70, 305-312 https:/doi.org/10.3109/00365513.2010.486442

Omar H. A., Chou C. C, Berman-Booty L. D., Ma Y., Hung J. H., Wang D., Kogure T., Patel T., Terracciano L., Muthusamy N. et al. (2011): Antitumor effects of OSU-2S, a non-immunosuppressive analogue of FTY720, in hepatocellular carcinoma. Hepatology 53, 1943-1958 https:/doi.org/10.1002/hep.24293

Pemberton C., Richards A. M. (2008): Biochemistry of ghrelin precursor peptides. Vitam. Horm. 77, 13-30 https:/doi.org/10.1016/S0083-6729(06)77002-9

Perry B. C., Soltys D., Toledo A. H., Toledo-Pereyra L. H. (2011): Tumor necrosis factor-alpha in liver ischemia/reperfusion injury. J. Invest. Surg. 24, 178-188 https:/doi.org/10.3109/08941939.2011.568594

Ren A. J., Guo Z. F., Wang Y. K., Lin L., Zheng X., Yuan W. J. (2009): Obestatin, obesity and diabetes. Peptides 30, 439-444 https:/doi.org/10.1016/j.peptides.2008.10.002

Şen L. S., Karakoyun B., Yeğen C., Akkiprik M., Yüksel M., Ercan F., Özer A., Yeğen B. C. (2015): Treatment with either obestatin or ghrelin attenuates mesenteric ischemia-reperfusion-induced oxidative injury of the ileum and the remote organ lung. Peptides 71, 8-19

https:/doi.org/10.1016/j.peptides.2015.04.014

Sepodes B., Maio R., Pinto R., Sharples E., Oliveira P., McDonald M., Yagoob M., Thiemermann C., Mota-Filipe H. (2006): Recombinant human erythropoietin protects the liver from hepatic ischemia reperfusion injury in the rat. Transplant. Int. 19, 919-926

https:/doi.org/10.1111/j.1432-2277.2006.00366.x

Serracino-Inglott F., Virlos I. T., Habib N. A., Williamson R. C. N., Mathie R. T. (2003): Differential nitric oxide synthase 
expression during hepatic ischemia-reperfusion. Am. J. Surg. 185, 589-595 https:/doi.org/10.1016/S0002-9610(03)00075-8

Shin T., Kuboki S., Huber N., Eismann T., Galloway E., Schuster R., Blanchard J., Pritts T. A., Lentsch A. B. (2008): Activation of peroxisome proliferator-activated receptor-gamma during hepatic ischemia is age-dependent. J. Surg. Res. 147, 200-205 https:/doi.org/10.1016/j.jss.2008.02.004

Soares J. B., Leite-Moreira A. F. (2008): Ghrelin, des-acyl ghrelin and obestatin: Three pieces of the same puzzle. Peptides 29, $1255-1270$ https:/doi.org/10.1016/j.peptides.2008.02.018

Sözen S., Kisakürek M., Yildiz F., Gönültaş M., Dinçel A. S. (2011) The effects of glutamine on hepatic ischemia reperfusion injury in rats. Hippokratia 15, 161-166

Subhas G., Gupta A., Bakston D., Silberberg B., Lobocki C., Andrus L., Decker M., Mittal V. K., Jacobs M. J. (2010): Protective effect of methylprednisolone on warm ischemia-reperfusion injury in a cholestatic rat liver. Am. J. Surg. 199, 377-381 https:/doi.org/10.1016/j.amjsurg.2009.09.012

Trovato L., Gallo D., Settanni F., Gesmundo I., Ghigo E., Granata R. (2014): Obestatin: is it really doing something? Front. Horm. Res. 42, 175-185 https:/doi.org/10.1159/000358346

Van Gulik T. M., De Graaf W., Dinant S., Busch O. R., Gouma D. J. (2007): Vascular occlusion techniques during liver resection. Dig. Surg. 24, 274-281 https:/doi.org/10.1159/000103658
Vollmar B., Glasz J., Leiderer R., Post S., Menger M. D. (1994): Hepatic microcirculatory perfusion failure is a determinant of liver dysfunction in warm ischemia-reperfusion. Am. J. Pathol. 145, 1421-1431

Wanner G. A., Ertel W., Müller P., Höfer Y., Leiderer R., Menger M. D., Messmer K. (1996): Liver ischemia and reperfusion induces a systemic inflammatory response through Kupffer cell activation. Shock 5, 34-40 https:/doi.org/10.1097/00024382-199601000-00008

Zhai Y., Shen XD., O‘Connell R., Gao F., Lassman C., Busuttil R. W., Cheng G., Kupiec-Weglinski J. W. (2004): Cutting Edge: TLR4 activation mediates liver ischemia/reperfusion inflammatory response via IFN regulatory factor 3-dependent MyD88-independent pathway. J. Immunol. 173, 7115-7119 https:/doi.org/10.4049/jimmunol.173.12.7115

Zhang J. V., Ren P. G., Avsian-Kretchmer O., Luo C.W., Rauch R., Klein C., Hsueh A. J. W. (2005): Obestatin, a peptide encoded by the ghrelin gene, opposes ghrelin's effects on food intake. Science 310, 996-999 https:/doi.org/10.1126/science.1117255

Zhou L., Zhu D. (2009): Neuronal nitric oxide synthase: structure, subcellular localization, regulation, and clinical implications. Nitric Oxide 20, 223-230 https:/doi.org/10.1016/j.niox.2009.03.001

Received: May 7, 2016

Final version accepted: July 8, 2016

First published online: November 30, 2016 